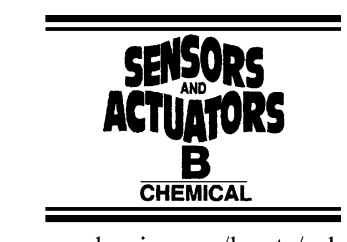

www.elsevier.com/locate/snb

\title{
Humidity sensing properties of a thick-film titania prepared by a slow spinning process
}

\author{
P.M. Faia*, C.S. Furtado, A.J. Ferreira \\ Department of Electrical Engineering and Computers, ICEMS Coimbra, LTMEU/FCT, University of Coimbra, \\ Polo 2, Pinhal de Marrocos, 3030-290 Coimbra, Portugal
}

Received 17 November 2003; received in revised form 26 February 2004; accepted 27 February 2004

Available online 27 April 2004

\begin{abstract}
A ceramic thick film humidity sensor was produced from an emulsion of titania powders by a spin coating technique using a low speed. Electrical measurements were taken between interdigital electrodes obtained by depositing silver paste on the oxide, then cured at $500{ }^{\circ} \mathrm{C}$ for $15 \mathrm{~min}$. Different relative humidities of a dynamic atmosphere were obtained by mixing dry and $23^{\circ} \mathrm{C}$ saturated synthetic air in convenient proportions. Complex impedance spectra of the titania sensor at various relative humidities (RH) and different temperatures were measured and compared. The humidity sensing behaviour is due to surface water molecules adsorption and capillary condensation. The proposed sensing mechanisms, explaining the registered impedance spectra, are a combination of proton hopping, hydronium electrical drift and diffusion, and electrolytic conduction. In the frequency range $1-400 \mathrm{~Hz}$, resistance and capacitive reactance show variations of three to four-order magnitude over the RH range 10-100\%. The curves representing the variations of resistance and capacitive reactance versus RH show clearly the existence of two dominant electrical charge transport mechanisms. A parameter called characteristic humidity is defined to represent the sensitive response of the sensor. It was found that the sensitivity was highly dependent on the frequency. This work also shows that, for the same $\mathrm{RH}$, both resistance and capacitive reactance vary with the atmosphere temperature.
\end{abstract}

(C) 2004 Elsevier B.V. All rights reserved.

Keywords: Humidity sensor; Titania; Thick film; Impedance spectroscopy

\section{Introduction}

Humidity is an important environmental characteristic which must be monitored and controlled either to maintain a comfortable living atmosphere in buildings or to improve the quality of production and products in industry and in medical care $[1,2]$. The relative humidity $(\mathrm{RH})$, which is the ratio of actual vapour pressure to the saturated vapour pressure at a given temperature, is the most frequently used parameter to specify humidity.

The materials used in humidity sensors are either polymeric or ceramic. These last ones show some superiority in performance because of its high chemical stability, wide range of operating temperatures and fast response to the changes of humidity [3]. Various mechanisms have been proposed to explain the variations of electrical impedance with humidity [4]. They take into account the chemisorbed and physisorbed layers of water molecules as well as the

\footnotetext{
* Corresponding author. Tel.: +351-2397-96200; fax: +351-2397-96247.

E-mail address: faia@deec.uc.pt (P.M. Faia).
}

capillary condensation of water inside tiny pores. The performance of a ceramic humidity sensor is strongly influenced by the porous microstructure and by the surface reactivity with water [5]. The presence of a large pore volume with a convenient pore size distribution is considered fundamental to achieve a high humidity sensitivity [6]. The sensing mechanism generally accepted for porous oxides at room temperature is of the ionic type [7]. The changes in impedance of porous ceramics at different environmental humidity values are related to the water adsorption mechanism on the oxide surface $[7,8]$. High porosity and a large surface area are desirable for improved sensitivity [9]. The importance of the pore-size distribution on the humidity-sensitive electrical response of porous ceramics has also been pointed out $[6,10]$.

Thick-film technology shows some advantages, such as, flexibility in choice of materials and design, low cost in automation and mass production and good reproducibility. The sensitivity of these humidity sensors depends on the microstructure which is related with the process of fabrication. The process used to make the sensor here presented is somehow a new one: a low speed spin coating of a powder 
emulsion on an alumina substrate. The choice of titania, $\mathrm{TiO}_{2}$ was due to the reported high sensitivity to humidity changes [11-13]. In order to determine the grain size and structural properties of the material X-ray diffraction (XRD), scanning electron microscopy, optical microscopy and porosimetry were used.

The sensor has been described in terms of sensitivity, frequency characteristics and temperature influence. The electrical response has been studied by using complex impedance spectroscopy [3,14]. Variations of electrical impedance were studied as a function of RH in the $0-100 \%$ range, at five different temperatures.

The full explanation of the electrical model adopted for the sensor will be presented in another paper.

\section{Experimental}

\subsection{Sensor preparation}

The thick film sensor was fabricated onto a clean polished alumina wafer with a diameter of $20 \mathrm{~mm}$ and a thickness of $3 \mathrm{~mm}$. Firstly, two electrodes were produced: silver paste, from Gwent Electronics (C80420D3), screen printed with an interdigital pattern, was dried at $150^{\circ} \mathrm{C}$ and then heated up at $850^{\circ} \mathrm{C}$ for $30 \mathrm{~min}$. An emulsion in acetone with ethyl cellulose as a temporary binder of as received $\mathrm{TiO}_{2}$ powder, from Fluka Ag (purity >99\%), was spin-coated onto the substrate at low speed $(250 \mathrm{rpm})$ for $30 \mathrm{~s}$. The coating procedure was repeated three times with intermediate drying and the burning off the organic binder of the previous layers at $150{ }^{\circ} \mathrm{C}$ for $15 \mathrm{~s}$. Afterwards, the deposited film was heated up in air up to $800^{\circ} \mathrm{C}$ at a constant rate of $10^{\circ} \mathrm{C} / \mathrm{min}$, and maintained at that temperature for $2 \mathrm{~h}$. Electrical lead wires were connected to the pads of the electrodes using once again silver paste.

\subsection{Humidity chamber}

The electrical characterisation of the sample was performed in a cylindrical chamber of alumina, $33 \mathrm{~cm}$ long, $3 \mathrm{~cm}$ diameter, provided with two aluminium lids, one of which traversed by electrical wires fixed with araldite. A constant relative humidity $(\mathrm{RH})$ was obtained by mixing water saturated air (synthetic air saturated with water vapour) with dry synthetic air in a given ratio. Water saturation of the air was realised by bubbling synthetic dry air through water contained inside a bottle (bubbler). Volumetric flow rates of both saturated wet and dry air were controlled and monitored by two independent flowmeters, between 0 and $104 \mathrm{ml} / \mathrm{min}$, and then intermixed in a mixer before passing tangentially over the surface of the sensor placed inside the test chamber. By this method the RH could be controlled up to $\pm 1 \%$ approximately. The test chamber, the airs' mixer and the bubbler were inside an oven, the temperature of which was electronically controlled better than $1{ }^{\circ} \mathrm{C}$.

\subsection{Measurements}

The sintered ceramic layer microstructure was characterised by using both light reflected and scanning electron microscopy. The optical microscope, Olympus, model BX $60 \mathrm{M}$, is equipped with a video camera connected to an image acquisition system based on a personal computer. The scanning electron microscope (SEM) used is a Philips model XL 30 TMP, operated at $30 \mathrm{kV}$. The structure of the $\mathrm{TiO}_{2}$ was identified by XRD by means of a diffractometer Philips model PW 3040/00 X'Pert with Co K $\alpha_{1}(\lambda=1.78897 \AA)$. The porosimetry of the specimen was determined with a porosimeter of Micrometrics, model Poresizer 9320.

The sample was placed inside a circular insert of the same diameter, drilled in a copper block $(40 \mathrm{~mm} \times 31 \mathrm{~mm} \times$ $11 \mathrm{~mm}$ ). Two cylindrical holes were opened in the block, one for the $100 \mathrm{~W}$ electrical heater and the other for the thermocouple. The temperature of the block cooper was measured by a chromel-alumel thermocouple and controlled by means of a temperature controller from Coreci (model ST48). Before any electrical measurement, at a given relative humidity and constant temperature, the corresponding flow was maintained for at least $60 \mathrm{~min}$. The sample was tested at 23, 40, 60,80 and $92^{\circ} \mathrm{C}$, respectively, at various $\mathrm{RH}$ values ranging from 0 to $100 \%$. The dependence of the electrical impedance of the sample on the relative humidity was investigated by using complex impedance spectroscopy. Impedance spectra were obtained in the range $100 \mathrm{~Hz}-40 \mathrm{MHz}$, with a peak voltage of $0.5 \mathrm{~V}$, by means of an impedance/gain-phase analyser, Hewlett-Packard (model HP4194A).

\section{Results and discussion}

\subsection{Microstructure}

The X-ray diffraction in Fig. 1 shows that the $\mathrm{TiO}_{2}$ phase in the film is anatase.

The representative microstructure of the sensing layer of the sample is shown in Figs. 2 and 3. The former (Fig. 2) is a light reflected micrograph on an etched surface of the sample obtained using a magnification of $100 \times$. The latter, (Fig. 3), is a SEM micrograph with a magnification of

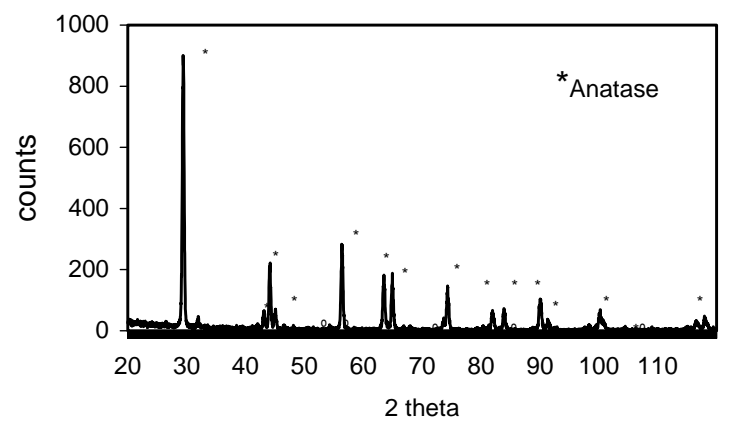

Fig. 1. XRD spectrum of the sample. 


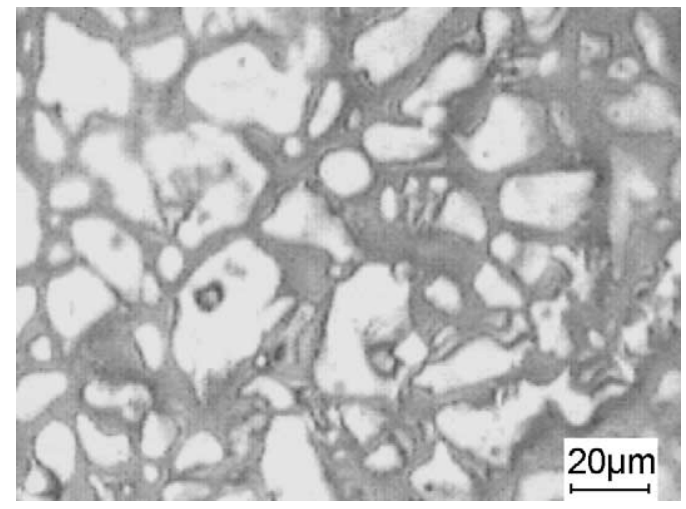

Fig. 2. Optical image of the sample at magnification $100 \times$.

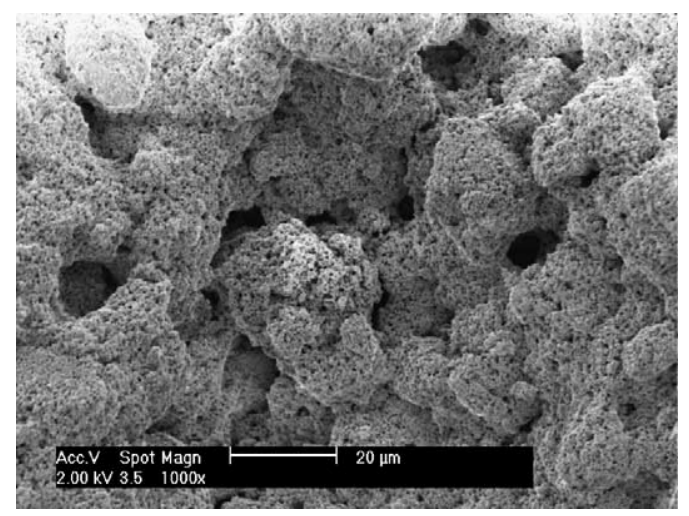

Fig. 3. SEM image of the sample at magnification $1000 \times$.

$1000 \times$. The grains seem to be in a random orientation. The microstructure is dominated by roughly round shaped grains. The average grain size was evaluated by the lineal intercept procedure from a micrograph of an etched sample surface.

The pore size distribution curve of the sample, obtained by the mercury intrusion method, is presented in Fig. 4. A trimodal distribution is observed with two regions suitable for capillary condensation: one below $40 \mathrm{~nm}$, the other between 80 and $1000 \mathrm{~nm}$. In humidity detection, capillary condensation of water vapour would occur only in the mesopore range $(20-1000 \AA)$. The pores with size above

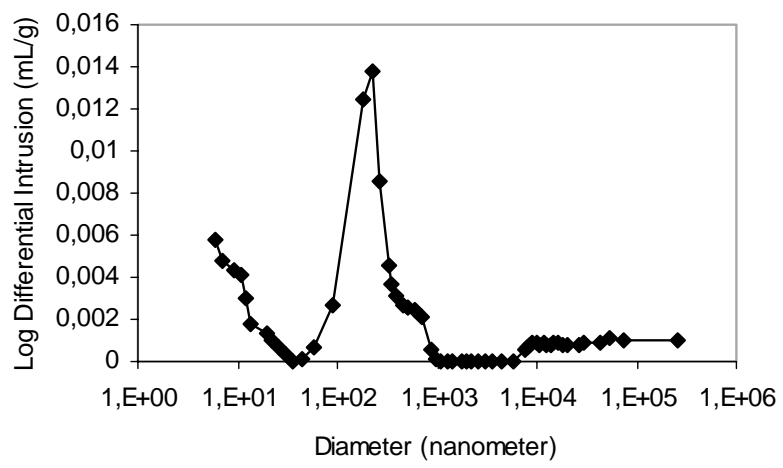

Fig. 4. Log differential intrusion as a function of pore diameter.
$10 \mu \mathrm{m}$ simply serve as passage for the water vapour. The grain size analysis based on ASTM E112 gives the following distribution: $0.99 \mu \mathrm{m}, 44 \% ; 1.4 \mu \mathrm{m}, 26 \%$; $1.99 \mu \mathrm{m}$, $15 \% ; 2.8 \mu \mathrm{m}, 8.1 \% ; 4 \mu \mathrm{m}, 3.1 \% ; 5.6 \mu \mathrm{m}, 1.4 \% ; 7.9 \mu \mathrm{m}$, $0.6 \%$; and above $15.8 \mu \mathrm{m}, 1.8 \%$. The thickness of the film was evaluated from the cross-section of the film and has been estimated around $130 \mu \mathrm{m}$.

\subsection{Cole-cole spectra}

The ac complex impedance measurements are particularly sensitive to the microstructure and to humidity changes. That is why this technique was used to investigate the sensitive properties of the $\mathrm{TiO}_{2}$ sample to $\mathrm{RH}$.

Cole-cole spectra of the complex impedance, $Z=R+$ $\mathrm{j} X$, of the $\mathrm{TiO}_{2}$ thick-film were recorded in the frequency range from $100 \mathrm{~Hz}$ to $40 \mathrm{MHz}$, with the relative humidity varying from 0 to $100 \%$, at the temperatures of $23,40,60$, 80 and $92{ }^{\circ} \mathrm{C}$, respectively. Fig. 5(a and b) represent the diagrams obtained at the extreme measuring temperatures, i.e. 23 and $92{ }^{\circ} \mathrm{C}$, respectively. It is known that a semicircle in an impedance spectroscopy diagram represents a resistor, $R$, in parallel with a capacitor, $C$. The angular frequency of the peak of the semicircle, $w_{\mathrm{p}}$, is such that $w_{\mathrm{p}} R C=1$. The values of the resistor and of the capacitor as well as the range of measuring frequency determine whether the semicircle is complete or not [15].
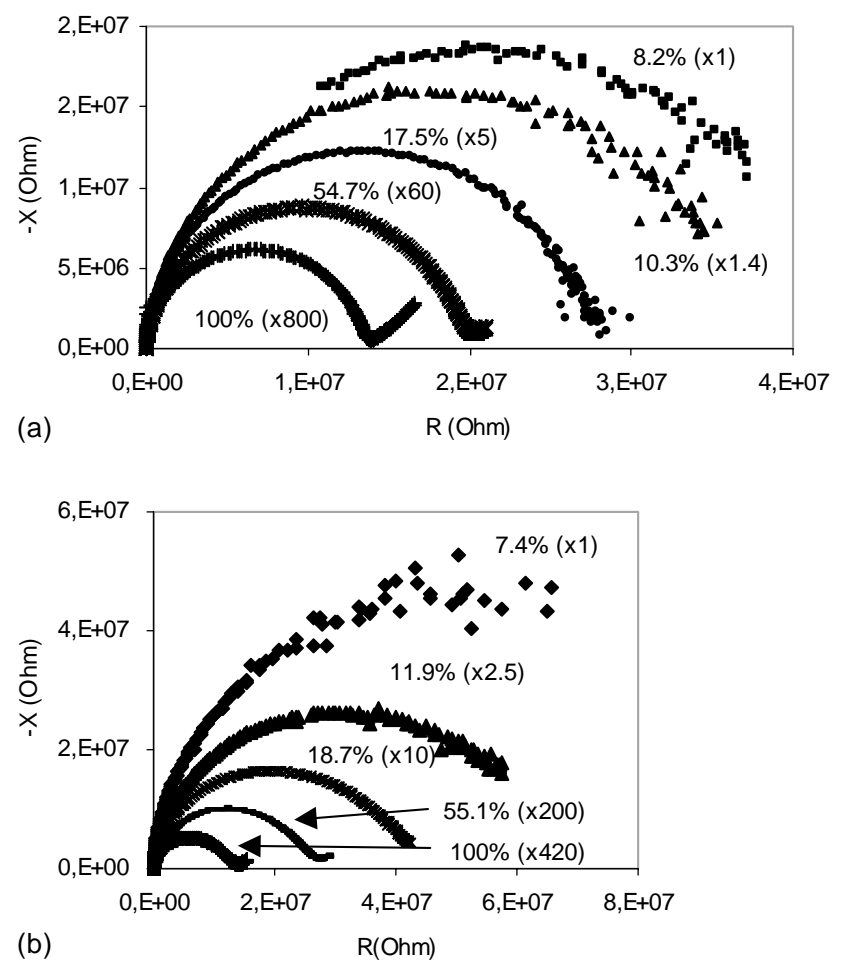

Fig. 5. (a) The impedance spectra of the sensor at the temperature of $23^{\circ} \mathrm{C}$ for different $\mathrm{RH}$ and (b) the impedance spectra of the sensor at the temperature of $92^{\circ} \mathrm{C}$ for different $\mathrm{RH}$. 


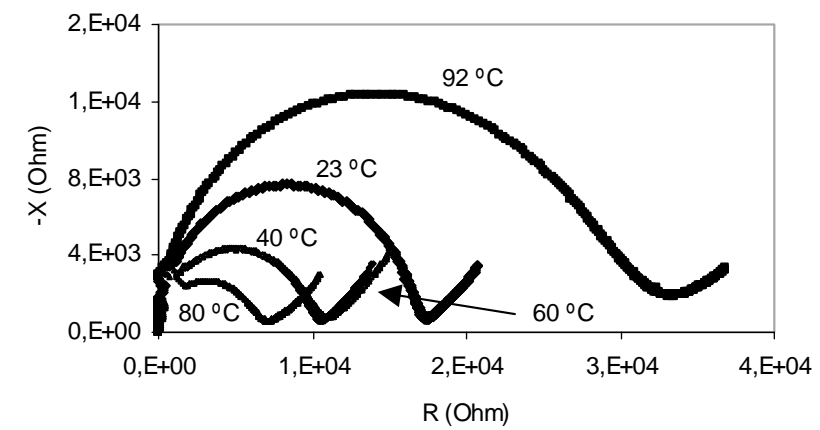

Fig. 6. Complex impedance spectra at $\mathrm{RH}=100 \%$ for the temperatures of $23,40,60,80$ and $92^{\circ} \mathrm{C}$.

In order to be included in the same plane, the diagrams are multiplied by appropriate factors (in parantheses). It is noticed that the arcs shrink with increasing RH. As a general feature at sufficiently high RH the complex impedance plots look approximately like an elongated semicircle. As RH increases a curved line appears at the low frequency range and the higher the $\mathrm{RH}$ is, the longer are the curved line and smaller the elongated semicircle.

This behaviour is explained by two relaxation mechanisms with not very different time constants plus a Warburg impedance in series with a capacitor. The full analysis of this observed behaviour supplemented with data obtained down to $0.1 \mathrm{~Hz}$ will be present in a further paper.

From these figures (Fig. 5(a and b)), it can be seen that, when RH is lower (less than 20-30\%), the complex impedance plot looks like an arc of circumference for the range of frequency from $100 \mathrm{~Hz}-40 \mathrm{MHz}$. As $\mathrm{RH}$ increases the elongation of the semicircle gets more noticeable and for higher RH (greater than 30-40\%) there is an inversion of curvatures and a curved inclined line appears. As can be seen the impedance plot decreases with increasing $\mathrm{RH}$.

In Fig. 6, spectra measured at $100 \% \mathrm{RH}$ but at different temperatures are shown. It can be seen (we will come to that later in Section 3.3.3) that, although the RH is the same and equal to $100 \%$, the spectra vary with the temperature.

\subsection{Humidity sensing properties}

\subsubsection{Humidity-resistance and humidity-capacitance characteristics}

Fig. 7(a) shows the humidity-resistance characteristics of the sensor, i.e. the variation of resistance as a function of $\mathrm{RH}$ at the temperatures of $23,40,60,80$ and $92^{\circ} \mathrm{C}$, respectively, measured at $100 \mathrm{~Hz}$.

Although, the measured values are not exactly the same for the same values of RH, they are not very different and the observable behaviour is rather similar. The resistance changes by about three to four-order magnitude when relative humidity varies from about 10 to $100 \%$. The resistance decreased more rapidly in the low $\mathrm{RH}$ range ( 0 to $\sim 40 \%$ ) than in the high one ( $\sim 40$ to $100 \%)$, as can be seen by the slopes of the curves in Fig. 7(a).
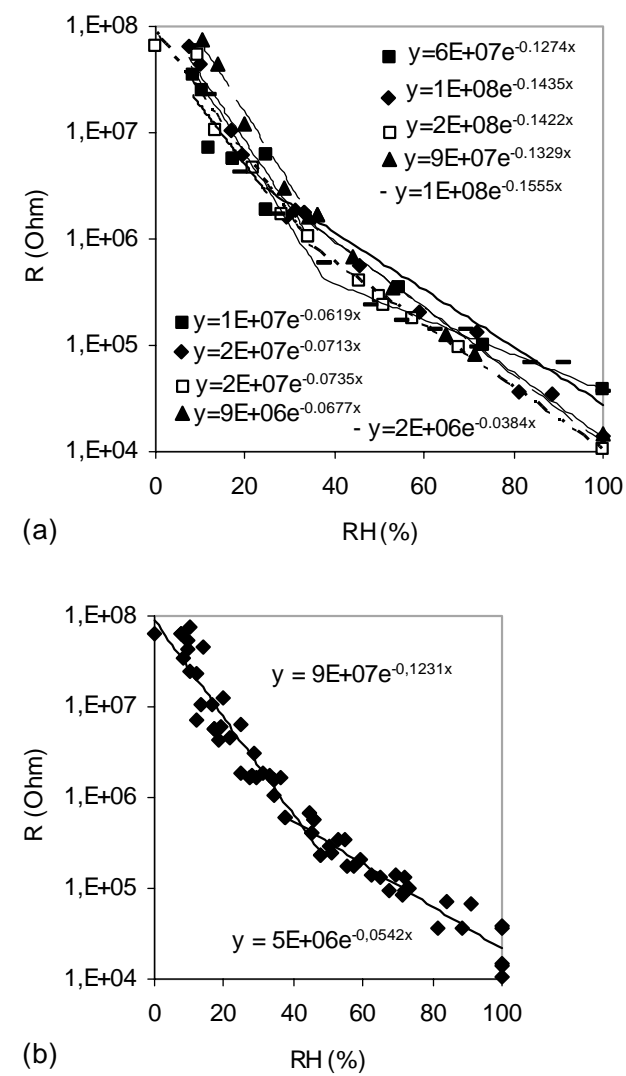

Fig. 7. (a) Dependency of the resistance of the sensor on relative humidity at $100 \mathrm{~Hz}$ at the temperatures of $23^{\circ} \mathrm{C}(\square), 40^{\circ} \mathrm{C}(\diamond), 60^{\circ} \mathrm{C}(\square), 80^{\circ} \mathrm{C}$ (A) and $92^{\circ} \mathrm{C}(\boldsymbol{C})$ and (b) dependency of the resistance of the sensor on relative humidity at $100 \mathrm{~Hz}$ for all the measuring temperatures.

In Fig. 7(b), all the experimental points at the different measuring temperatures are shown. It can be observed that altogether the differences observed at the various temperatures are not very relevant.

The experimental points are well fitted by two exponential relationships: one for the lower $\mathrm{RH}(0$ to $\sim 40 \%)$, the other for the higher $\mathrm{RH}(\sim 40$ to $100 \%)$. At all temperatures, the slope of the straight-lines in the plane $(\mathrm{RH}, \log R)$ referring to the lower values of $\mathrm{RH}$ is greater that the corresponding to the higher values (see Table 1).

A parameter called characteristic relative humidity, $\mathrm{CH}$ (\%), can be defined for the sensor by the relation

$R=R_{0} \mathrm{e}^{-\mathrm{RH}(\%) \mathrm{CH}(\%)}$

where $R_{0}$ is the resistance for $\mathrm{RH}=0 \%$.

Table 1

The values of $\mathrm{CH}(\%)$ for lower and higher $\mathrm{RH}$ at various temperatures

\begin{tabular}{lll}
\hline Temperature $\left({ }^{\circ} \mathrm{C}\right)$ & $\begin{array}{l}\text { Lower } \mathrm{RH}(0 \\
\text { to } \sim 40 \%)\end{array}$ & $\begin{array}{l}\text { Higher } \mathrm{RH} \\
(\sim 40 \text { to } 100 \%)\end{array}$ \\
\hline 23 & 0.2047 & 0.0616 \\
40 & 0.1435 & 0.0713 \\
60 & 0.1365 & 0.0672 \\
80 & 0.1637 & 0.0669 \\
92 & 0.1539 & 0.0295 \\
\hline
\end{tabular}




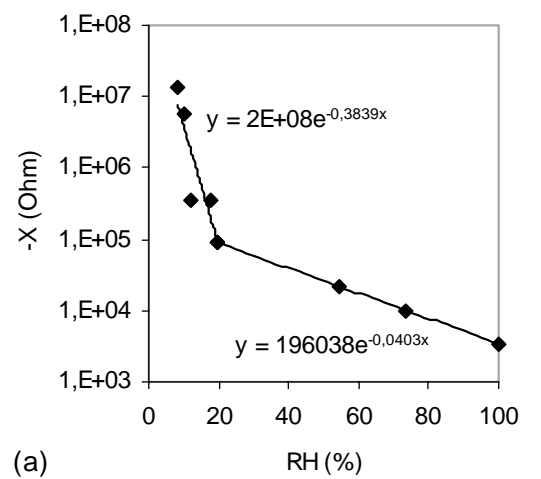

(a)

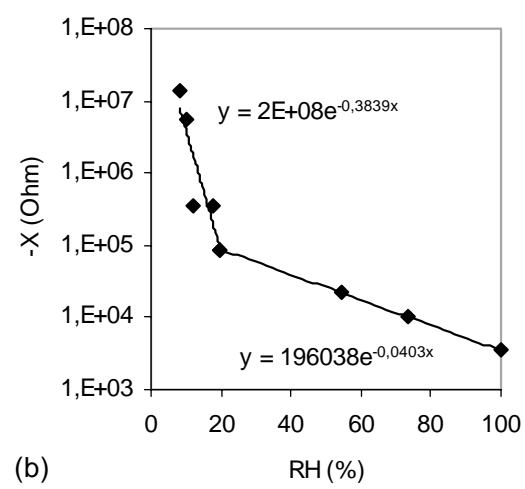

Fig. 8. Dependency of the capacitive reactance of the sensor on relative humidity at $100 \mathrm{~Hz}$ for the temperatures of (a) $23^{\circ} \mathrm{C}$ and (b) $92^{\circ} \mathrm{C}$.

Similar behaviour to the one observed for the resistance was recorded for the capacitive reactance, as can be seen in Fig. 8(a and b).

\subsubsection{Frequency characteristics}

It must be underlined that the electrical characteristics of the thick-film humidity sensor were measured in ac fields, as the dc resistance increases monotonically to infinity due to water polarisation. It is observed that the RH sensitivity depends on the frequency at which the impedance is measured. Fig. 9(a and b) show the variation of the resistance and capacitive reactance, respectively, with $\mathrm{RH}$, at $23^{\circ} \mathrm{C}$, for the frequencies of $1,10,100,1000$ and $10,000 \mathrm{~Hz}$. At 1 and $10 \mathrm{~Hz}$, the values have been calculated from the electrical circuit which best fits the experimental data.

In Fig. 9(a), it can be seen that up to $1000 \mathrm{~Hz}$, the values of the resistance are quite similar, with the sensitivity showing the same good behaviour. This is not the case for the frequencies 10,000 and $100,000 \mathrm{~Hz}$. That is the reason why $100 \mathrm{~Hz}$ has been chosen as the operating frequency. It can be concluded that the humidity-resistance characteristics of the thick-film humidity sensor are strongly affected by the measuring frequencies. The frequency characteristic of the humidity sensor is also dependent of the humidity range: at low humidity the sensor resistance is strongly affected by the frequency. In fact, it has already been noticed that the $\mathrm{RH}$ sensitive electrical response of these materials depended on the frequency at which the resistance is measured [16].
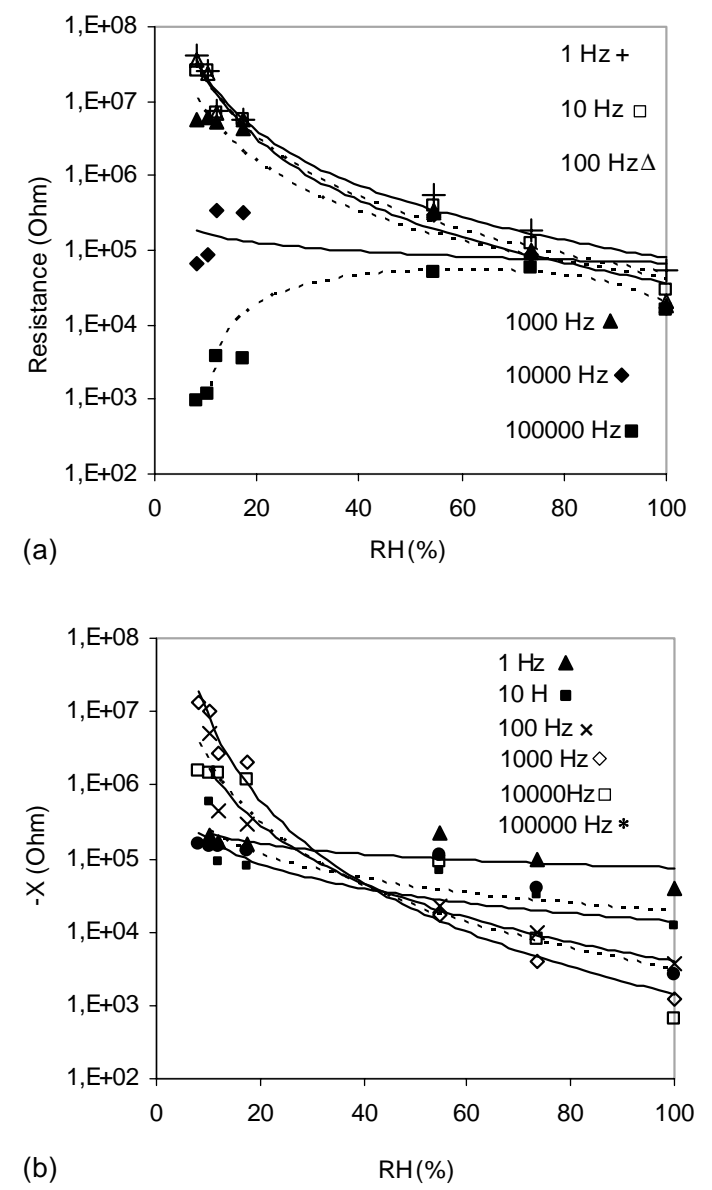

Fig. 9. (a) Resistance and (b) capacitance reactance dependence on the RH at $23^{\circ} \mathrm{C}$ for the frequencies of $1,10,100,1000,10,000$ and $100,000 \mathrm{~Hz}$.

Thus, it is possible to modify their response to $\mathrm{RH}$ by choosing the frequency at which the resistance is measured. The RH sensing properties of this type of film are tunable with the frequency, a feature which is among those of the intelligent materials.

Fig. 9(b) exhibits the variation of the measured capacitive reactance of the sensor, $\mathrm{X}$, with $\mathrm{RH}$, for different frequencies at the temperature of $23{ }^{\circ} \mathrm{C}$. Here, the best sensitivities are observed for the frequencies of 100, 1000 and 10,000 Hz.

\subsubsection{Temperature dependence}

To determine whether the temperature at which the $\mathrm{RH}$ is considered influences the resistance, measurements were made at $100 \mathrm{~Hz}$ and at five different ambient temperatures: 23, 40, 60, 80 and $92^{\circ} \mathrm{C}$, respectively. Fig. 10 shows that the variations of resistance with temperature are not very significant for the same RH. It can be seen that for the lower values of $\mathrm{RH}(0,10$ and $20 \%)$ the resistance is maximum for $60{ }^{\circ} \mathrm{C}$; for the higher $\mathrm{RH}(60,80$ and $100 \%)$ the maximum is registered at $40^{\circ} \mathrm{C}$.

Fig. 11( $a$ and $b$ ) exhibit the variation of the measured resistance and capacitive reactance with frequency for different temperatures at the RH equal to $100 \%$. Again it can be 


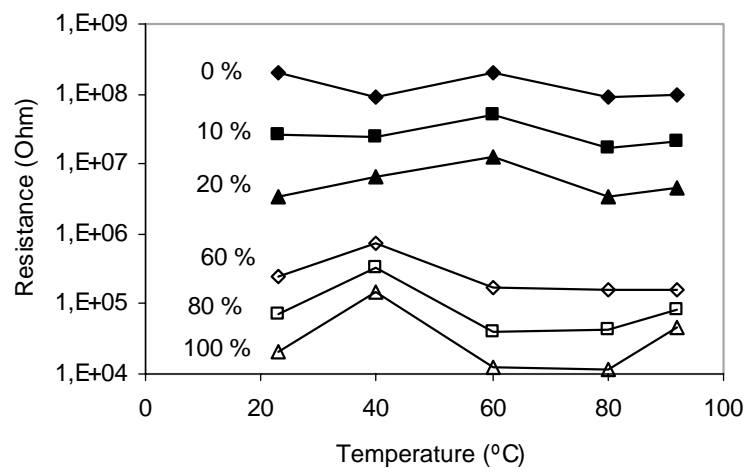

Fig. 10. Resistance dependence on temperature at $100 \mathrm{~Hz}$ for $\mathrm{RH}=0$, $10,20,60,80$ and $100 \%$.

observed that for the same RH the results depend on the temperature of the atmosphere. It is noticeable that the response in resistance is not so dependent on the temperature as it happens in the case of the capacitive reactance. In the latter case, it can be pointed out that the peak of the curves shows an obvious variation with temperature, which happens at different frequencies.

To confirm whether a lowering of the impedance happens around $60^{\circ} \mathrm{C}$, a dynamic analysis was performed: impedance spectra (see Fig. 12) were registered with temperature increasing from 50 up to $70^{\circ} \mathrm{C}$. From the initial instant, at $50{ }^{\circ} \mathrm{C}$, the impedance decreased monotonically up to $30 \mathrm{~min}$. After then, an increase is noticed up to the final value, taken at $70^{\circ} \mathrm{C}, 1 \mathrm{~h}$ and $35 \mathrm{~min}$ later. This means that between 50 and $70^{\circ} \mathrm{C}$ a minimum takes place.

(a)
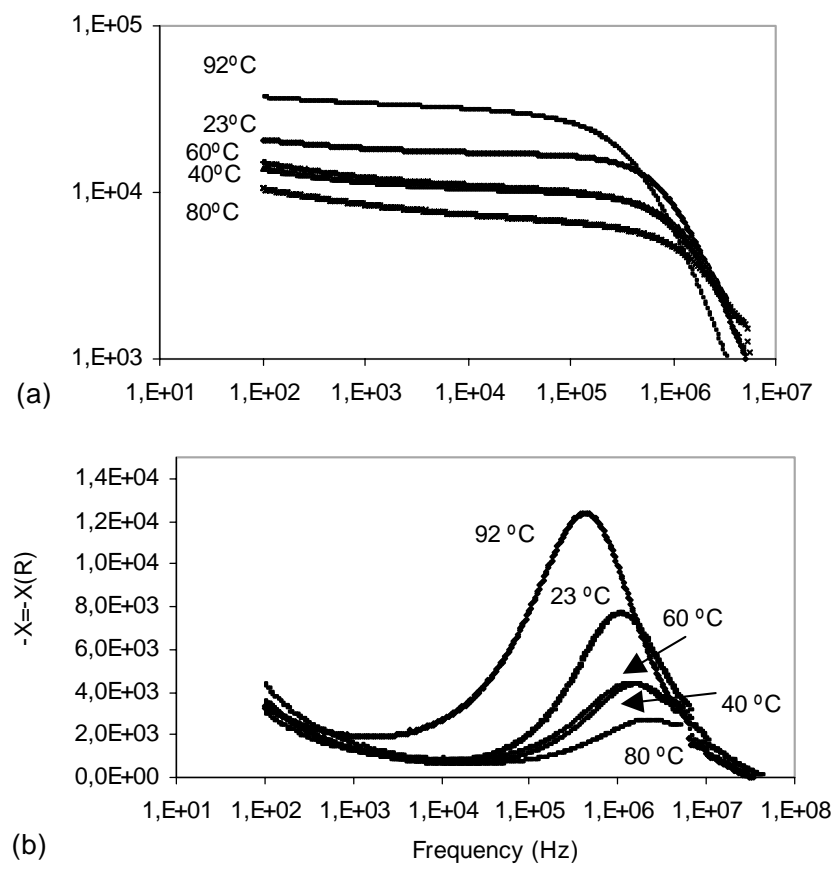

Fig. 11. (a) Resistance and (b) capacitance dependence on frequency, at $\mathrm{RH}=100 \%$, for the temperatures of $23,40,60,80$ and $92^{\circ} \mathrm{C}$.

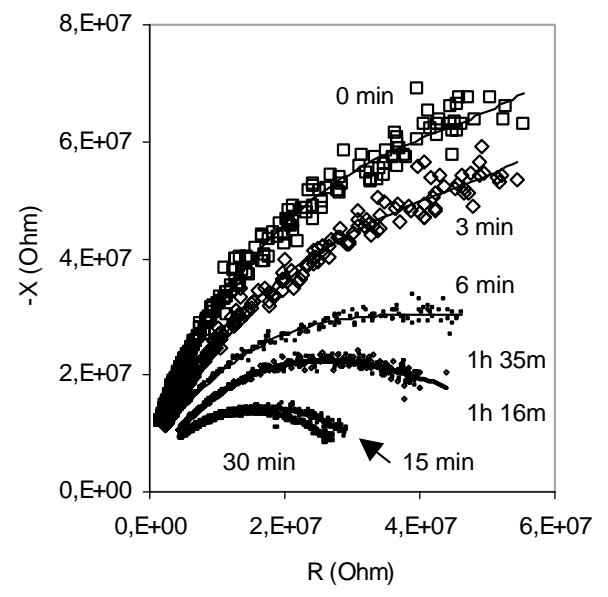

Fig. 12. Evolution of the impedance plots from 50 up to $70^{\circ} \mathrm{C}$, at $14 \%$ RH.

\subsection{Discussion}

Our experimental data can be explained by a physical model based on adsorbed water on the surface and on capillary water condensation within the pores $[1,17]$. A porous structure of the ceramic promotes this process. The adsorption can be divided into two stages: chemisorption and physisorption. Since water is a polar molecule, the negatively charged oxygen is electrostatically attached to the positively charged $\mathrm{Ti}^{4+}$ ions of the sensor material. The initial monolayer is chemisorbed due to formation of a chemical bond under the influence of high electrostatic field between $\mathrm{Ti}^{4+}$ and oxygen of the water layer. This layer, once formed, is not further affected by exposure to humidity, being difficult to remove. Thus, the concentration of chemisorbed water should be the same as that of outermost cations. At a low humidity, water vapour chemisorbs by a dissociation mechanism, forming hydroxyl ions at the surface [3]. Usually, an additional monolayer is added by $20 \%$ humidity with many more added at even higher humidity [18]. These physisorbed layers are easily removed by decreasing the humidity.

With a further increase in humidity, the multi-layers of physisorbed water molecules tend to condense in the capillary pores which have dimensions below the Kelvin radius [4]. The number of physisorbed water layers and hence the concentration of $\mathrm{H}^{+}$ions increases with increase of water vapour. The neck of the pore is filled or unfilled depending on its radius and thickness of the physisorbed layer and hence RH [19]. It has been reported that the capillary condensation of water vapour would occur in the mesopore range only [20].

At the lower RH, the charge transport is secured by proton hopping between chemisorbed hydroxyl groups. Afterwards, when the amount of physisorbed water molecules starts to appear, the hydronyum ion, $\mathrm{H}_{3} \mathrm{O}^{+}$, is most likely the charge carrier. Further at higher RH, at medium to high humidity, $\mathrm{H}_{3} \mathrm{O}^{+}$ions will be hydrated into $\mathrm{H}^{+}$ions and $\mathrm{H}_{2} \mathrm{O}$ and each 
water molecule will be slightly bonded with one hydroxyl group. The charge transport occurs when $\mathrm{H}_{3} \mathrm{O}^{+}$ions release a proton to neighbouring water molecules, which accepts it while releasing another proton and so on. This is known as the Grotthuss's chain reaction [7,21,22]. At higher humidity levels physisorbed water layers show a liquid-like behaviour and $\mathrm{H}^{+}$ions move freely. If we have micropore condensation, the mechanism of conduction through the pores is electrolytic in nature and will occur in addition to the Grotthuss mechanism. Electrolytic conduction in the condensed water within the pores combined with charge diffusion at the walls of the pores originates a sort of Warburg impedance with a power dependence of resistance on humidity, with lower values for this power dependence. This succession of mechanisms leads to a rapid increase in conduction (decrease in resistance) with increasing humidity content.

Our experimental data, above presented, are explained by these adsorption and charge transport mechanisms. The impedance spectra are useful for understanding the involved sensing mechanisms. The complex impedance spectra (Figs. $5(a$ and $b$ ) and 6 ) as well as the dependency of the resistance (Fig. 7(a and b)) and capacitive reactance (Fig. 8(a and b)) on RH can be understood on the basis of two different relaxation transport processes and a diffusion process, which have $\mathrm{H}_{3} \mathrm{O}^{+}$or $\mathrm{H}^{+}$as the main charge carriers. In the frequency range $100 \mathrm{~Hz}-40 \mathrm{MHz}$, at lower $\mathrm{RH}$, one polarization mechanism explains the registered spectra; in the middle RH range, two polarization mechanisms govern the charge transport; at higher RH, then charge diffusion starts to have a role. The second polarization mechanism is switched on at RH $20 \%$, approximately. Then as RH increases, above RH $50 \%$, the electrolytic charge transport in the condensed water within the pores and the charge transfer to the walls of the pores starts to become important and only through a sort of Warburg impedance $[22,23]$ our results can be explained. Then, see (Figs. 5(a and b) and 6), our data can only be understood through a sort of Warburg impedance.

It must be remarked that it is also above $50 \%$, when the condensed water within the pores starts to be significant, that the values of the resistance are nearly the same for the large range of frequencies $1 \mathrm{~Hz}-100 \mathrm{kHz}$ (Fig. 9(a)). It is also noticed (Fig. 9(b)) that it is also around RH 50\% that the capacitive reactance curves obtained in the same frequency range $1 \mathrm{~Hz}-100 \mathrm{kHz}$ cross each other.

Yet we have investigated, still, we did not find a thorough treatment in the literature, whether the sensitive behaviour was dependent on the atmosphere temperature. In Fig. 10, the higher values of the resistance occurring around $60^{\circ} \mathrm{C}$ for the lower $\mathrm{RH}$ and around $40^{\circ} \mathrm{C}$ for the higher $\mathrm{RH}$ could be assigned to the first peak of desorption of water molecules which takes place within the temperature range $32-90^{\circ} \mathrm{C}$ [24]. Fig. 11(a and b) show clearly, in the case of RH $100 \%$, that both resistance and capacitive reactance vary with temperature, being this variation frequency dependent. In order to reduce the temperature influence, the measuring frequency must be conveniently chosen.

\section{Conclusion}

This paper documents the preparation and humidity sensing properties of a ceramic thick film of titania, $\mathrm{TiO}_{2}$. This thick film was prepared by a very simple technique: spinning coating with low speed of a powder emulsion on an alumina wafer. The film possesses a pore distribution with an appreciable volume of mesopores, adequate for water condensation. The cole-cole plots of the complex impedance of the titania film support the existence of charge transport on the chemisorbed and physisorbed layers of water and also in the condensed water within the pores. On the other hand, the plots of resistance and capacitive reactance with RH demonstrate that two transport mechanisms are dominant. The titania thick film exhibits good humidity sensitive properties, since in the range of RH 10-100\% both the resistance and capacitive reactance of the titania film change by three to four-orders magnitude. A new parameter, called characteristic relative humidity is defined: its value is approximately $15 \%$ for RH between 0 and around $40 \%$ and equal to approximately $6 \%$ in the range of $\mathrm{RH} 40-100 \%$. It was observed that the response of the sensor varies with frequency, which implies a criterious choice of the measuring frequency. For the same RH, the sensing response varied with temperature. An equivalent electrical circuit modelling the various charge transport mechanisms will be present in another paper.

\section{References}

[1] B.M. Kulwicky, Humidity Sensors, J. Am. Ceram. Soc. 74 (1991) 697-708.

[2] S. Yang, J. Wu, $\mathrm{ZrO}_{2}-\mathrm{TiO}_{2}$ ceramic humidity sensors, J. Mater. Sci. 26 (1991) 631-636.

[3] S. Agarwal, G.L. Sharma, Humidity sensing properties of (Ba, Sr) $\mathrm{TiO}_{3}$ thin films grown by hydrothermal-electrochemical method, Sens. Actuators B 85 (2002) 205-211.

[4] E. Traversa, Ceramic sensors for humidity detection: the state-of-the-art and future developments, Sens. Actuators B 23 (1995) $135-156$.

[5] G. Fu, H. Chen, Z. Chen, J. Zhang, H. Kohler, Humidity sensitive characteristics of $\mathrm{Zn}_{2} \mathrm{SnO}_{4}-\mathrm{LiZnVO}_{4}$ thick films prepared by the sol-gel method, Sens. Actuators B 81 (2002) 308-312.

[6] Y. Shimizu, H. Arai, T. Seiyama, Theoretical studies on the impedance-humidity characteristics of ceramic humidity sensors, Sens. Actuators 7 (1985) 11-22.

[7] J.H. Anderson, G.A. Parks, The Electrical conductivity of silica gel in the presence of adsorbed water, J. Phys. Chem. 72 (1968) 3362 3368.

[8] E. McCafferty, A.C. Zettlemoyer, Adsorption of water vapour on $\alpha-\mathrm{Fe}_{2} \mathrm{O}_{3}$, Discuss. Faraday Soc. 52 (1971) 239-263.

[9] E. Traversa, A. Bearzotti, A novel humidity-detection mechanism for $\mathrm{ZnO}$ dense pellets, Sens. Actuators B 23 (1995) 181-186.

[10] T.Y. Kim, D.H. Lee, Y.C. Shim, J.U. Bu, S.T. Kim, Effects of alkaline oxide additives on the microstructure and humidity sensitivity of $\mathrm{MgCr}_{2} \mathrm{O}_{4}-\mathrm{TiO}_{2}$, Sens. Actuators B 9 (1992) 221-225.

[11] G. Montesperelli, A. Pumo, E. Traversa, G. Gusmano, A. Bearzotti, A. Montenero, G. Gnappi, Sol-gel processed $\mathrm{TiO}_{2}$-based thin films as innovative humidity sensors, Sens. Actuators B 24-25 (1995) 705-709. 
[12] Y.C. Yeh, T.Y. Tseng, D.A. Chang, Electrical properties of porous titania ceramic humidity sensors, J. Am. Ceram. Soc. 72 (1989) $1472-1475$.

[13] K. Katayama, H. Hasegawa, T. Takahashi, T. Akiba, H. Yanagida, Humidity sensitivity of $\mathrm{Nb}_{2} \mathrm{O}_{5}$-doped $\mathrm{TiO}_{2}$ ceramics, Sens. Actuators A 24 (1990) 55-60.

[14] J.E. Bauerle, Study of solid electrolyte polarization by a complex admittance method, J. Phys. Chem. Solids 30 (1969) 2657-2670.

[15] K.Al. Abdullah, A. Bui, A. Loubier, Low frequency and low temperature behaviour of $\mathrm{ZnO}$-based varistor by impedance measurement, J. Appl. Phys. 69 (1991) 4046-4052.

[16] E. Traversa, Design of ceramic materials for chemical sensors with novel properties, J. Am. Ceram. Soc. 78 (1995) 2625-2632.

[17] B.M. Kulwicki, Ceramic sensors and transducers, J. Phys. Chem. Solids 45 (1984) 1015-1031.

[18] W.M. Sears, The effect of oxygen stoichiometry on the humidity sensing characteristics of bismuth iron molybdate, Sens. Actuators B 67 (2000) 161-172.

[19] G.F. James, R.W.A. Vasantha, Reliability and reproducibility of ceramic sensors. Part III. Humidity sensors, Am. Ceram. Soc. Bull. 72 (1993) 119-129.

[20] K-S. Chou, T.-K. Lee, F.-J. Liu, Sensing mechanism of a porous ceramic as humidity sensor, Sens. Actuators B 56 (1999) 106-111.

[21] J.J. Fripiat, A. Jelli, G. Poncelet, J. Andre, Thermodynamic properties of adsorbed water molecules and electrical conduction in montmorillonites and silicas, J. Phys. Chem. 69 (1965) 2185-2197.

[22] W. Qu, W. Wlodarski, J.-U. Meiyer, Comparative study on micromorphology and humidity sensitive properties of thin-film and thick-film sensors based on semiconducting $\mathrm{MnWO}_{4}$, Sens. Actuators B 64 (2000) 76-82.
[23] Y.C. Yeh, T.Y. Tseng, Analysis of the dc and ac properties of $\mathrm{K}_{2} \mathrm{O}$-doped porous $\mathrm{Ba}_{0.5} \mathrm{Sr}_{0.5} \mathrm{TiO}_{3}$ ceramic humidity sensor, J. Mater. Sci. 24 (1989) 2739-2745.

[24] M. Egashira, S. Kawasuni, S. Kagawa, T. Seiyama, Temperature programmed desorption study of water adsorbed on metal oxides. 1 . Anatase and rutile, Bull. Chem. Soc. Jpn. 51 (1978) 3144-3149.

\section{Biographies}

Pedro M. Faia received his degree in Electrical Engineering in 1990, his MS in Automation in 1994 and his PhD in Electronic Materials in 2003 from the University of Coimbra. He is an auxiliary professor at the Department of Electrical Engineering and Computers of the University of Coimbra where his research interests concern the research and development of solid state chemical sensors, sensor integration techniques and software projects development for VLSI technology.

Carlos S. Furtado received a degree in D Phil in Physics from Oxford University in 1971 and an Aggregation degree from Coimbra University in1974. He is a full time professor at the Department of Electrical Engineering and Computers of the University of Coimbra with interests in electronic ceramics and gas sensors.

António J. Ferreira graduated in Electrical Engineering in 1976 and received his $\mathrm{PhD}$ in 1994 from the University of Coimbra. He is currently associate professor at the Department of Electrical Engineering and Computers of the University of Coimbra, with interests in various areas of electrical properties of materials, ferrites, ceramics and gas sensors, having particular interest in impedance spectroscopy analysis technique. 